(c) American Dairy Science Association, 2006.

\title{
A Survey of Extractable Persistent Organochlorine Pollutants in Chinese Commercial Yogurt
}

\author{
H. Zhang, ${ }^{\star} \dagger$ Z. F. Chai, ${ }^{\star}{ }^{1}{ }^{1}$ H. B. Sun, ${ }^{\star}$ and J. L. Zhang \\ *Institute of Nuclear Application, Science College of Shenzhen University, Shenzhen 518060, China \\ tKey Laboratory of Nuclear Analytical Techniques and Laboratory of Biological Safety, Institute of High Energy Physics, \\ Chinese Academy of Sciences, Beijing 100049, China
}

\section{ABSTRACT}

Eighteen Chinese commercial brands of yogurt were collected from supermarkets from December 2002 to April 2003, for characterization of organochlorine pesticides (OCP) and polychlorinated biphenyls (PCB). Besides monitoring OCP and PCB by gas chromatography, the levels of extractable persistent organochlorine (EPOCl; i.e., sulfuric acid-resistant $\mathrm{EPOCl}$ ) were also determined by instrumental neutron activation analysis. The results indicated that the contamination pattern of the selected OCP and PCB were in the order of dichlorodiphenyltrichloroethanes $($ DDT $) \approx$ hexachlorocyclohexanes $(\mathrm{HCH})>>$ aldrin $\geq$ chlordanes $\geq$ heptachlor epoxide and 4-6 chlorinated biphenyls (CB) $>>$ 7-10 CB, respectively. Furthermore, $\beta-\mathrm{HCH}$, and 1,1dichloro-2,2-bis ( $\mathrm{p}$-chlorophenyl) ethylene were the predominant isomers of $\mathrm{HCH}$ and DDT residues in yogurt, and PCB with 4,4'- and 2,3,5- substitution patterns were the predominant congeners of $\mathrm{PCB}$ residues. Also, the results indicated that the mean level of total chlorine in the identified organochlorine species was below $4 \%$ of EPOCl in yogurt, which implied that more than $96 \%$ of EPOCl measured in yogurt samples could not be accounted for by selected OCP and PCB.

Key words: yogurt, extractable persistent organochlorine, organochlorine pesticide, polychlorinated biphenyl

\section{INTRODUCTION}

Dairy products supply lipophilic polychlorinated biphenyls (PCB) and organochlorinated pesticides (OCP) that accumulate in human tissues (Jacobs et al., 2004). Since the Stockholm Convention, a global treaty aiming to protect human health and the environment from persistent organic pollutants (POP) entered into force on May 17, 2004, the potential health risk to the public

Received September 30, 2005.

Accepted December 1, 2005.

${ }^{1}$ Corresponding author: chaizf@ihep.ac.cn from the residues of POP has raised a widespread international concern.

Currently, yogurt is considered a main component of the Chinese diet because of its health benefits and taste. Yogurt is not only an indicator of POP in pasture and forages, but also one of the major sources of POP entering the human body, thereby causing serious health problems (Wong and Lee, 1997). Thus, monitoring contaminant levels in dairy products is imperative for quantifying dietary exposure to POP. Although there is an extensive and growing body of data on the presence of POP in dairy products including milk and butter (Venant et al., 1991; Kalantzi et al., 2001), little information is available in the literature about the concentrations of $\operatorname{OCP}(\alpha-, \beta-, \gamma$ - and $\delta$-hexachlorocyclohexanes (HCH), 1,1,1-trichloro-2,2-bis (p-chloro-phenyl) ethane (p, $\mathbf{p}^{\prime}$-DDT), 1,1-dichloro-2,2-bis (p-chlorophenyl) ethylene (p, $\mathbf{p}^{\prime}$-DDE), and 1,1-dichloro-2,2-bis (p-chlorophenyl) ethane (p,p'-DDD), aldrin, heptachlor epoxide, cisand trans-chlordane) and PCB (PCB60, 103, 105, 128, $143,154,173,202,205,208$, and 209) in yogurt. In particular, concentrations of extractable persistent organochlorine (EPOCl) in the food supply are poorly understood. This study reports the levels of EPOCl and selected PCB and OCP in 18 commercial brands of yogurt, and discusses possible reasons for the occurrence of the predominant species of $\mathrm{HCH}$, DDT, and $\mathrm{PCB}$ residues in yogurt.

\section{MATERIALS AND METHODS}

\section{Sample Collection and Preparation}

Eighteen Chinese commercial brands of yogurt were randomly collected from supermarkets of Beijing and Shenzhen, China, from December 2002 to April 2003. For each brand, 8 to 10 cups (about 1,000 to 1,250 g) were treated as soon as they were brought back to laboratory. Same-brand yogurt samples were pooled in petri dishes and freeze-dried until constant weight. The lyophilized yogurt was milled into a homogeneous powder, then stored in a brown glass bottle at $-4^{\circ} \mathrm{C}$ until use. 


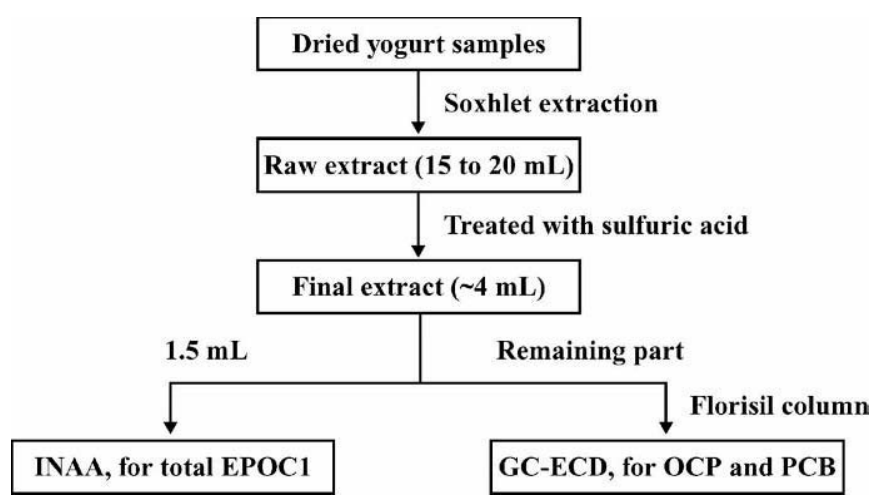

Figure 1. Flow chart for analysis of organohalogens in yogurt by a combination of instrumental neutron activation analysis (INAA), gas chromatography-electron capture detector (GC-ECD), and chemical separation. OCP = Organochlorine pesticides, $\mathrm{PCB}=$ polychlorinated biphenyls, EPOC1 = extractable persistent organochlorine.

\section{Chemicals}

The quantitative standards of $\mathrm{OCP}(\alpha-, \beta-, \gamma-$, and $\delta$ $\mathrm{HCH}$, heptachlor epoxide, aldrin, cis-chlordane, transchlordane, $\mathrm{p}, \mathrm{p}^{\prime}$-DDE, $\mathrm{p}, \mathrm{p}^{\prime}$-DDD, and $\mathrm{p}, \mathrm{p}^{\prime}-\mathrm{DDT}$ ) and PCB (PCB60, 103, 105, 128, 143, 154, 173, 202, 205, 208, and 209) were authentic reference materials purchased from Supelco (Bellefonte, PA). The purity of each standard was greater than $99.3 \%$. All solvents (analytical reagent grade) including acetone, cyclohexane, and nhexane were redistilled before use. Concentrated sulfuric acid (guaranteed reagent grade) was extracted by cyclohexane before use. Anhydrous sodium sulfate (analytical reagent grade) was heated in an oven at $650^{\circ} \mathrm{C}$ for $5 \mathrm{~h}$ before use. Florisil (Supelco) was first heated in an oven at $675^{\circ} \mathrm{C}$ for $5 \mathrm{~h}$, deactivated with $3 \mathrm{~mL}$ of distilled water, and then sealed in a beaker for $24 \mathrm{~h}$ before use. The $\mathrm{Cl}$ standard was prepared by dissolving the appropriate amount of $\mathrm{KCl}$ [guarantee reagent (content $>99.99 \%)$ ] in redistilled water $(1.0 \mu \mathrm{g} / \mathrm{mL})$. The standard solutions of OCP and PCB were prepared by gradually diluting the original solutions of OCP and PCB in distilled $n$-hexane. None of the procedures were conducted in plastic ware to prevent contamination with external organic pollutants. Laboratory glassware was washed with acid and detergents, rinsed with distilled water and acetone, and then dried in an oven prior to use.

\section{Analysis}

Extraction and Cleanup. The entire experimental procedure, outlined in Figure 1, is based on a combination of instrumental neutron activation analysis (INAA) and gas chromatography (GC) with chemical separation (Xu et al., 2003). In brief, approximately 10 $\mathrm{g}$ of dried yogurt was weighed, and Soxhlet-extracted with $250 \mathrm{~mL}$ of a mixture of cyclohexane and acetone (1:1) for $14 \mathrm{~h}$. The crude extract was washed with $1 \%$ sodium sulfate to remove acetone. The aqueous phases were again extracted with fresh cyclohexane, and the organic phases were combined and concentrated to approximately 15 to $20 \mathrm{~mL}$ by rotary evaporation. The raw extract was treated repeatedly with concentrated sulfuric acid until a clear and colorless cyclohexane extract was obtained, which was then washed with redistilled water, dried with anhydrous sodium sulfate, and concentrated to about $4 \mathrm{~mL}$ by rotary evaporation. A $1.5-\mathrm{mL}$ aliquot of the 4-mL final extract was taken for determination of total EPOCl. The remaining extract was analyzed for OCP and PCB by Florisil column chromatography (Calamari et al., 1994). The column was prewashed with $20 \mathrm{~mL}$ of $\mathrm{n}$-hexane; the remaining extract was eluted with $50 \mathrm{~mL}$ of $\mathrm{n}$-hexane, concentrated by rotary evaporation, and evaporated to $0.5 \mathrm{~mL}$ under a gentle flow of nitrogen (99.999\%).

Analysis of OCP and PCB. The GC analyses were carried out on a Varian 3800 gas chromatograph (Varian Ltd., Palo Alto, CA) equipped with a ${ }^{63} \mathrm{Ni}$ electron capture detector, using a fused silica capillary column (CP-Sil 5 CB Low Bleed/MS, $30 \mathrm{~m} \times 0.25 \mathrm{~mm}$ i.d., with $0.25 \mu \mathrm{m}$ film thickness). The temperature program was $130^{\circ} \mathrm{C}$ for $1 \mathrm{~min}$, increased at $10^{\circ} \mathrm{C} / \mathrm{min}$ to $200^{\circ} \mathrm{C}$, increased at $3^{\circ} \mathrm{C} / \mathrm{min}$ to $230^{\circ} \mathrm{C}$, increased at $10^{\circ} \mathrm{C} / \mathrm{min}$ to $270^{\circ} \mathrm{C}$, and held for $7 \mathrm{~min}$. Injector temperature was $270^{\circ} \mathrm{C}$ and detector temperature was $300^{\circ} \mathrm{C}$. Helium and oxygen-free nitrogen (99.999\%) were used as carrier and makeup gas, respectively. Peak identification was conducted by comparing the GC retention time with those of authentic standards, and quantification of OCP and PCB were made by external standard method calibrated with a 5-point calibration curve encompassing the entire concentration range. The detection limits, on the basis of a signal-to-noise ratio of $3: 1$, were between 0.01 to 0.06 and 0.002 to $0.06 \mu \mathrm{g} / \mathrm{kg}$ for 11 OCP and 11 PCB standards, respectively; low enough to determine the selected $\mathrm{OCP}$ and $\mathrm{PCB}$ residues at the required levels in this study.

Analysis of EPOCl. The concentrations of EPOCl, expressed as chloride, were determined by INAA according to the methods reported by Xu et al. (2003). In brief, the samples and standards were sealed in polyethylene capsules and sent into the irradiation channel of the miniature neutron source reactor of the Institute of Atomic Energy, Beijing, China. To minimize the radioactivity background, the samples were transferred to a new counting vial after irradiation. The analyses were based on $\gamma$-peak from ${ }^{38} \mathrm{Cl}\left(\mathrm{t}_{1 / 2}=37.24 \mathrm{~min}, \mathrm{E}_{\gamma}=\right.$ $1,642 \mathrm{keV})$. For INAA, the samples were irradiated for $15 \mathrm{~min}$, cooled for $2 \mathrm{~min}$, and counted for $15 \mathrm{~min}$. The 
$\gamma$-energy spectra were measured with a high-purity germanium detector with associated electronics interfaced to a computer-controlled EG\&G Ortec multichannel analyzer (EG\&G Ortec, Oak Ridge, TN) for peak area calculations. The chlorine content was calculated by the relative method. The ${ }^{24} \mathrm{Na}\left(\mathrm{t}_{1 / 2} 15.0 \mathrm{~h}, \mathrm{E}_{\gamma}=2754\right.$ $\mathrm{keV}$ ) was simultaneously determined as a control for the contamination caused by inorganic chlorine (Gether et al., 1979). In this study ${ }^{24} \mathrm{Na}$ was not found in the extracts. The detection limit of INAA for $\mathrm{Cl}$ was $50 \mathrm{ng}$.

Quality Control. Analyses were performed in a series of 5 samples and 1 blank. Each analysis of each brand of yogurt sample was performed in 2 to 4 replicates. For the recovery tests, the yogurt samples were spiked with the target analytes after thorough extraction with the mixture of cyclohexane and acetone (1:1) for $14 \mathrm{~h}$, followed by the same processing as the real samples. The recovery $(\mathrm{n}=3)$ of $11 \mathrm{OCP}$ ranged from 81 to $99 \%$, with relative standard deviations of 5.7 to $10.7 \%$, and of 11 PCB ranged from 71 to $100 \%$, with relative standard deviations of 7.1 to $10.8 \%$. Laboratory blanks of all solvents and chemicals were also carefully checked. No significant peaks overlapping OCP and PCB standards appeared in the chromatogram of the blank run.

\section{RESULTS AND DISCUSSION}

\section{OCP in 18 Commercial Yogurt Samples}

The mean concentrations of the detectable target OCP in the yogurt samples are listed in Table 1 . The contamination patterns of the selected OCP were in the order of DDT (detecting frequency $=100 \%) \approx \mathrm{HCH}$ $(100 \%)>>$ aldrin $(25 \%) \geq$ chlordanes $(65 \%) \geq$ heptachlor epoxide (55\%). Although levels of $\mathrm{HCH}$ and DDT residues are well below the China Dairy Guidelines (both $\mathrm{HCH}$ and DDT are $\leq 100 \mu \mathrm{g} / \mathrm{L} ; \mathrm{GB} 6914-1986$ ), they were still the predominant OCP in the yogurt samples; together, they accounted for 77.9 to $100 \%$ of total OCP.

The levels of $\mathrm{HCH}$ (mean value $=0.6 \mu \mathrm{g} / \mathrm{kg}$ of fresh weight) and DDT residues $(0.5 \mu \mathrm{g} / \mathrm{kg})$ in yogurt samples were much lower than those previously reported in Chinese milk in 2001 ( $\mathrm{HCH}=35 \mu \mathrm{g} / \mathrm{kg}$ of fresh weight and $\mathrm{DDT}=46 \mu \mathrm{g} / \mathrm{kg}$; Zhong et al., 2003) and in $1992(\mathrm{HCH}=$ $70 \mu \mathrm{g} / \mathrm{kg}$ and DDT = $95 \mu \mathrm{g} / \mathrm{kg}$; Zhang, 1995). The reasons for the remarkable reduction of $\mathrm{HCH}$ and DDT residues in yogurt can be generally attributed to the banning of $\mathrm{HCH}$ and DDT in agriculture practice, leading to a steady decline in residue levels in food (Chen and Gao, 1993). On the other hand, the manufacturing technology of yogurt, including heat treatments (pasteurization and sterilization), and the action of microorganisms during storage can result in reduction of $\mathrm{HCH}$ and DDT residues in yogurt. A reduction of lindane and its metabolites have been observed in yogurt during pasteurization, boiling, and sterilization, and a gradual reduction of lindane was observed during storage (Abou-Arab, 1999). In addition, DDT residues were reduced by the isolated Ras cheese microorganisms, Streptococci, Lactobacilli, and yeast (Abou-Arab, 1997).

$\boldsymbol{H C H}$. The average levels of $\mathrm{HCH}$ isomers in 18 brands of yogurt specimens were in the order of $\beta-\mathrm{HCH}$ $(12.8 \mu \mathrm{g} / \mathrm{kg}$ of lipid $)>>\gamma-\mathrm{HCH}(5.8 \mu \mathrm{g} / \mathrm{kg}$ of lipid $) \approx \alpha-$ $\mathrm{HCH}(5.2 \mu \mathrm{g} / \mathrm{kg}$ of lipid $) \geq \delta-\mathrm{HCH}(4.6 \mu \mathrm{g} / \mathrm{kg}$ of lipid $)$, which correlated with their bioconcentration factors in mammalian fat $(\beta-\mathrm{HCH}=527>\alpha-\mathrm{HCH}=20 \approx \gamma$ $\mathrm{HCH}=19>\delta-\mathrm{HCH}=8.5$; Geyer et al., 1987). The high concentration of $\beta$-HCH was believed to be due to its comparatively high stability and low water solubility. Also, its all-equatorial configuration favors storage in biological media and affords it greater resistance to hydrolysis and enzymatic degradation. Willett et al. (1998) observed that $\beta-\mathrm{HCH}$ was also the major species in animal tissues and fluids and a similar finding was reported in human breast milk (Kumaran et al., 1990).

DDT. The predominant species in yogurt was p, $\mathrm{p}^{\prime}-$ DDE, which comprised $84 \%$ of total DDT. The DDT individuals in yogurt samples, except for sample no. 6 , decreased in the order of $p, p^{\prime}-\mathrm{DDE}>\mathrm{p}, \mathrm{p}^{\prime}$-DDT $>\mathrm{p}, \mathrm{p}^{\prime}-$ DDD. This was in agreement with the half-lives of DDT individuals measured in cows by Fries (1977) who demonstrated that DDE was persistent, but not DDT, which was metabolized in the rumen to DDD. By a contaminant mass balance experiment of a lactating cow in its natural state, McLachlan (1993) also reported that virtually all of the cow's exposure to DDT was through feed (more than 98\%), and 50 to $80 \%$ of the ingested $\mathrm{p}, \mathrm{p}^{\prime}-\mathrm{DDE}$ were excreted via milk, and only $4 \%$ of the $p, p^{\prime}-D D T$.

\section{Risk Evaluation of Detected OCP to Human Health}

To understand the magnitude of exposure to detected OCP via Chinese commercial yogurt, the mean daily intakes of HCH, DDT, heptachlor epoxide, chlordanes, and aldrin were estimated based on ingestion of $500 \mathrm{~g} /$ $\mathrm{d}$ of yogurt (according to the Chinese recommended 500 $\mathrm{mL} / \mathrm{d}$ of milk ingestion for an adult). The estimated mean daily intakes of $\mathrm{HCH}(0.28 \mu \mathrm{g})$, DDT $(0.27 \mu \mathrm{g})$, heptachlor epoxide $(0.01 \mu \mathrm{g})$, chlordans $(0.02 \mu \mathrm{g})$, and aldrin $(0.02 \mu \mathrm{g})$ are very low in comparison to the acceptable daily intakes of WHO/FAO $(1978,1998)$ for HCH $(840 \mu \mathrm{g})$, DDT $(1200 \mu \mathrm{g})$, heptachlor epoxide (30 $\mu \mathrm{g})$, chlordans $(60 \mu \mathrm{g})$, and aldrin $(6 \mu \mathrm{g})$. Such a low daily intake of these pollutants via yogurt indicates the insignificant exposure of OCP from yogurt to local residents. However, the acceptable daily intakes are based on an "acceptable" risk to human health. This 
Table 1. The average concentrations (and range) of organochlorine pesticides (OCP) in 18 Chinese commercial yogurt samples

\begin{tabular}{|c|c|c|c|c|c|c|c|c|c|c|c|c|c|}
\hline \multirow[b]{2}{*}{$\begin{array}{l}\text { Sample } \\
\text { no. }\end{array}$} & \multicolumn{13}{|c|}{$\mathrm{OCP}^{1}(\mu \mathrm{g} / \mathrm{kg}$ of lipid $)$} \\
\hline & $\alpha-\mathrm{HCH}$ & $\beta-\mathrm{HCH}$ & $\gamma-\mathrm{HCH}$ & $\delta$-HCH & $\mathrm{HCH}$ & $\begin{array}{l}\mathrm{p}, \mathrm{p}^{\prime}- \\
\mathrm{DDE}\end{array}$ & $\begin{array}{l}\mathrm{p}, \mathrm{p}^{\prime}- \\
\mathrm{DDT}\end{array}$ & $\begin{array}{l}\mathrm{p}, \mathrm{p}^{\prime}- \\
\text { DDD }\end{array}$ & DDT & $\begin{array}{l}\text { Heptachlor } \\
\text { epoxide }\end{array}$ & $\begin{array}{l}\text { Cis- } \\
\text { chlordan }\end{array}$ & $\begin{array}{l}\text { Trans- } \\
\text { chlordan }\end{array}$ & Aldrin \\
\hline \multirow[t]{2}{*}{1} & 3.5 & 9.7 & 5.0 & 1.6 & 19.9 & 54.4 & 2.1 & 1.0 & 57.5 & ND & ND & 1.2 & ND \\
\hline & $3.4-3.6$ & $9.2-10.2$ & $4.9-5.2$ & ND-3.2 & $17.4-22.2$ & $50.7-58.2$ & $2.1-2.1$ & $0.9-1.0$ & $53.8-61.3$ & & & $1.2-1.2$ & \\
\hline \multirow[t]{2}{*}{2} & 18.8 & 46.4 & 9.5 & 16.3 & 91.1 & 71.7 & 4.7 & 3.3 & 79.7 & 0.6 & ND & ND & 2.1 \\
\hline & $18.7-19.0$ & $46.2-46.7$ & $9.0-10.0$ & $16.2-16.4$ & $90.6-91.6$ & $69.1-74.3$ & $4.7-4.7$ & $3.3-3.3$ & $77.1-82.3$ & ND-1.2 & & & $2.0-2.2$ \\
\hline \multirow[t]{2}{*}{3} & 3.3 & 0.2 & 4.0 & 3.3 & 10.8 & 3.1 & 0.5 & 0.4 & 4.0 & ND & 1.3 & ND & 1.7 \\
\hline & $2.7-5.3$ & ND-0.3 & $3.0-5.8$ & $2.1-6.1$ & $8.3-17.2$ & $2.4-4.4$ & ND-1.8 & ND- 0.8 & $2.4-5.3$ & & ND-3.4 & & ND-4.3 \\
\hline \multirow[t]{2}{*}{4} & 7.3 & 15.8 & 6.4 & 5.4 & 34.9 & 22.7 & 4.2 & 1.5 & 28.4 & ND & 1.8 & 0.5 & 3.5 \\
\hline & $6.2-8.6$ & $14.0-17.6$ & $5.7-6.7$ & $4.1-6.7$ & $31.4-39.0$ & $20.0-26.1$ & $3.4-4.9$ & $1.3-1.7$ & $24.9-32.5$ & & ND-3.6 & ND-1.9 & $2.3-4.5$ \\
\hline \multirow[t]{2}{*}{5} & 3.1 & 2.7 & 3.4 & 3.1 & 12.2 & 6.9 & 0.9 & 0.2 & 8 & 0.9 & ND & ND & ND \\
\hline & $2.0-3.7$ & $2.2-3.4$ & $2.3-3.9$ & $2.0-3.7$ & $8.5-14.7$ & $4.5-8.8$ & ND-2.6 & ND-0.3 & $4.8-10.0$ & ND-1.7 & & & \\
\hline \multirow[t]{2}{*}{6} & 2.0 & 1.7 & 2.3 & 1.0 & 7.2 & 4.8 & 0.04 & 0.2 & 5.0 & 0.6 & ND & ND & ND \\
\hline & $1.4-2.6$ & $0.1-2.6$ & $1.7-3.2$ & ND-2.0 & $6.0-8.0$ & $3.5-5.8$ & ND-0.06 & ND- 0.3 & $3.5-5.8$ & ND-0.9 & & & \\
\hline \multirow[t]{2}{*}{7} & 3.5 & 29.4 & 4.9 & 2.5 & 40.4 & 31.8 & 3.8 & 2.8 & 38.3 & ND & ND & 1.3 & ND \\
\hline & $3.3-3.8$ & $26.8-32.1$ & $4.6-5.2$ & $2.3-2.7$ & $37.0-43.8$ & $28.4-35.2$ & $3.5-4.0$ & $2.5-3.0$ & $34.4-42.2$ & & & $1.2-1.4$ & \\
\hline \multirow[t]{2}{*}{8} & 5.8 & 18.4 & 6.7 & 6.1 & 37 & 19.4 & 4.1 & 1.5 & 25.0 & 1.3 & ND & ND & ND \\
\hline & $5.3-6.2$ & $16.4-20.5$ & $6.6-6.8$ & $5.8-6.3$ & $4.4-39.6$ & $17.9-20.9$ & $3.8-4.4$ & $1.4-1.6$ & $23.1-27.0$ & $1.3-1.3$ & & & \\
\hline \multirow[t]{2}{*}{9} & 4.9 & 13.5 & 5.6 & 5.8 & 29.8 & 22.2 & 2.6 & 1.4 & 26.2 & 1.1 & ND & 0.6 & 1.9 \\
\hline & $4.4-5.5$ & $12.6-14.5$ & $4.6-6.5$ & $5.0-6.6$ & $26.6-33.1$ & $21.3-23.1$ & $2.1-3.1$ & $1.2-1.5$ & $24.6-27.7$ & $1.0-1.3$ & & ND-1.2 & $1.7-2.2$ \\
\hline \multirow[t]{2}{*}{10} & 12.4 & 39.2 & 10.6 & 9.1 & 71.2 & 40.1 & 6.9 & 2.6 & 49.6 & ND & ND & ND & ND \\
\hline & $11.9-12.9$ & $37.7-40.8$ & $10.1-11.0$ & $8.8-9.4$ & $68.4-74.1$ & $39.6-40.5$ & $6.8-7.1$ & $2.6-2.6$ & $49.0-50.2$ & & & & \\
\hline \multirow[t]{2}{*}{11} & 2.6 & 0.6 & 4.0 & ND & 7.2 & 4.1 & 1.5 & 0.4 & 6.0 & 1.0 & ND & ND & ND \\
\hline & $2.6-2.6$ & $0.6-0.6$ & $3.9-4.1$ & & $7.1-7.2$ & $4.0-4.3$ & $1.4-1.5$ & $0.4-0.4$ & $5.8-6.2$ & $0.9-1.0$ & & & \\
\hline \multirow{2}{*}{12} & 3.2 & 3.6 & 4.6 & ND & 11.4 & 11.7 & 1.9 & 1.2 & 14.8 & 1.2 & ND & ND & ND \\
\hline & $3.1-3.2$ & $3.6-3.6$ & $4.5-4.7$ & & $11.3-11.4$ & $11.1-12.2$ & $1.8-2.0$ & $1.2-1.3$ & $14.1-15.5$ & $1.1-1.3$ & & & \\
\hline \multirow[t]{2}{*}{13} & 3.8 & ND & 8.5 & 3.5 & 15.8 & 12.5 & 2.4 & 0.5 & 15.5 & ND & ND & 1.6 & ND \\
\hline & $3.5-4.1$ & & $8.0-8.9$ & $3.0-3.9$ & $14.6-17.0$ & $11.6-13.4$ & $2.2-2.7$ & $0.5-0.6$ & $14.8-16.1$ & & & $1.4-1.8$ & \\
\hline \multirow[t]{2}{*}{14} & 4 & ND & 7.4 & 3.6 & 15.1 & 26.8 & 2.4 & 0.9 & 30.1 & ND & 1.4 & & ND \\
\hline & $2.8-5.3$ & & $6.0-8.7$ & $2.5-4.8$ & $11.2-18.9$ & $24.4-29.3$ & $2.0-2.8$ & $0.4-1.3$ & $26.8-33.4$ & & ND-2.7 & ND-3.2 & \\
\hline \multirow[t]{2}{*}{15} & 5.2 & 2.8 & 8.6 & 3.7 & 20.2 & 32.0 & 3.4 & 0.7 & 36.0 & ND & ND & & 3.5 \\
\hline & $4.6-5.7$ & $2.5-3.0$ & $8.1-9.1$ & $3.2-4.2$ & $18.5-22.0$ & $29.6-34.4$ & $2.9-3.8$ & $0.6-0.8$ & $33.0-39.0$ & & & $1.9-2.5$ & $2.9-4.1$ \\
\hline \multirow[t]{2}{*}{16} & 3 & 7.3 & 3.7 & 2.6 & 16.6 & 10.7 & 1.7 & 0.6 & 13 & 0.7 & ND & & ND \\
\hline & $2.7-3.2$ & $6.6-8.1$ & $3.6-3.8$ & $2.4-2.7$ & $15.3-17.8$ & $9.1-12.3$ & $1.6-1.8$ & $0.5-0.7$ & $11.2-14.8$ & $0.7-0.7$ & & $0.9-1.1$ & \\
\hline \multirow{2}{*}{17} & 2.7 & 5.1 & 3.4 & 2.4 & 13.6 & 12 & 1.2 & 0.5 & 13.8 & 0.8 & ND & & ND \\
\hline & $2.6-2.7$ & $5.1-5.1$ & $3.4-3.5$ & $2.1-2.7$ & $13.2-14.0$ & $11.0-13.1$ & $1.2-1.3$ & $0.4-0.5$ & $12.6-14.9$ & $0.8-0.9$ & & $0.9-1.1$ & \\
\hline \multirow[t]{2}{*}{18} & 3.9 & 8.1 & 6.2 & 3.1 & 21.4 & 13.7 & 2.0 & & 16.4 & & ND & & ND \\
\hline & $3.6-4.2$ & $7.8-8.4$ & $5.8-6.6$ & $3.0-3.2$ & $20.2-22.5$ & $13.0-14.4$ & $1.9-2.1$ & $0.6-0.7$ & $15.6-17.2$ & $0.6-1.2$ & & $0.8-1.4$ & \\
\hline
\end{tabular}

${ }^{1} \mathrm{OCP}$ : organochlorine pesticides; $\alpha-\beta-, \gamma-\delta$-HCH: $\alpha-\beta-, \gamma-, \delta$-hexachlorocyclohexane; $\mathrm{p}, \mathrm{p}^{\prime}$-DDEE: 1,1-dichloro-2,2-bis (p-chlorophenyl) ethylene; $\mathrm{p}, \mathrm{p}^{\prime}$-DDT: 1,1,1-trichloro-2,2bis (p-chlorophenyl) ethane; $\mathrm{p}, \mathrm{p}^{\prime}$-DDD: 1,1 -dichloro-2,2-bis (p-chlorophenyl) ethane; HCH $=\alpha-+\beta-+\gamma-+\delta$-HCH; DDT $=\mathrm{p}, \mathrm{p}^{\prime}-\mathrm{DDE}+\mathrm{p}, \mathrm{p}^{\prime}-\mathrm{DDT}+\mathrm{p}, \mathrm{p}^{\prime}-\mathrm{DDD} ; \mathrm{ND}=\mathrm{Not}$ detected. 
Table 2. The average concentrations (and range) of selected polychlorinated biphenyls (PCB) in 18 Chinese commercial yogurt sample

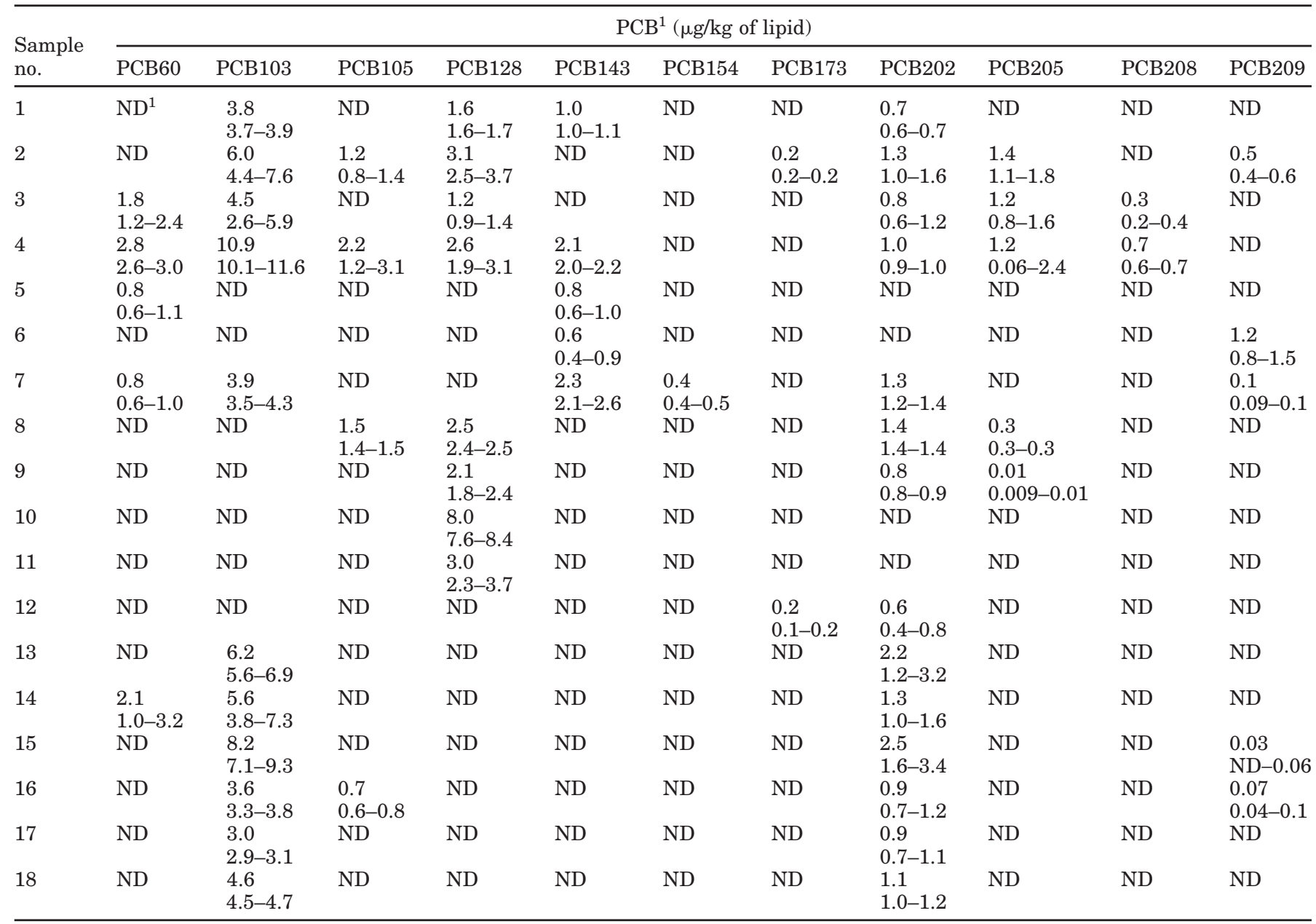

${ }^{1} \mathrm{ND}=$ Not detected.

does not mean zero risk. For endocrine-disrupting chemicals, including $\mathrm{HCH}$, DDT, heptachlor epoxide, chlordans, and aldrin, there may be no safe doses, just as there are no safe doses of carcinogens (ENDS, 1997).

\section{PCB in 18 Chinese Commercial Yogurt Samples}

The mean concentrations of the PCB in 18 retail yogurts are listed in Table 2. The results indicated that about 44 to $81 \%$ of total PCB was attributed to PCB103; PCB202, detected in $78 \%$ of yogurt specimens, was the most frequently detected congener among the target PCB. Figure 2 also shows that the contamination pattern of the selected PCB in yogurt was in the order of $4-6 \mathrm{CB}>>7-10 \mathrm{CB}$. The higher proportions of $4-6 \mathrm{CB}$ congeners reflected the historical use of $\mathrm{PCB}_{5}$ in China. It was reported that approximately 10,000 tons of PCB were produced in China from 1965 to 1974 (Qin et al., 2003). The Chinese technical $\mathrm{PCB}_{5}$, with similar composition to Aroclor 1,254 (a commercial European mix- ture, containing approximately $21 \% 4-\mathrm{CB}, 48 \% 5-\mathrm{CB}$, $23 \% 6-\mathrm{CB}$, and 6\% 7-CB; Jiang et al., 1997) have been widely used in industry as heat-transfer fluids, hydraulic lubricants, dielectric fluids, and transformer oil. The variable compositions of $\mathrm{PCB}$ in yogurt implied that there were different sources of PCB inputs in the different areas such as $\mathrm{PCB}_{3}$ (similar to Aroclor 1,242) or other commercial mistures of PCB.

It has been found that the metabolism of PCB in mammals occurs by hydroxylation at the 2- and 4-positions through the hepatic cytochrome P-448 and P-450 enzyme systems, respectively (Matthews and Dedrick, 1984). McLachlan (1993) further demonstrated that 4hydroxy-PCB were the primary metabolites of several congeners in cows and indicated that the presence of a chlorine atom at the 4-position, or the presence of chlorine atoms at both the adjacent 3- and 5-positions, would inhibit the formation of the intermediate arene oxide at the 4-position. This is in agreement with our observations; that is, the substitution patterns of the 


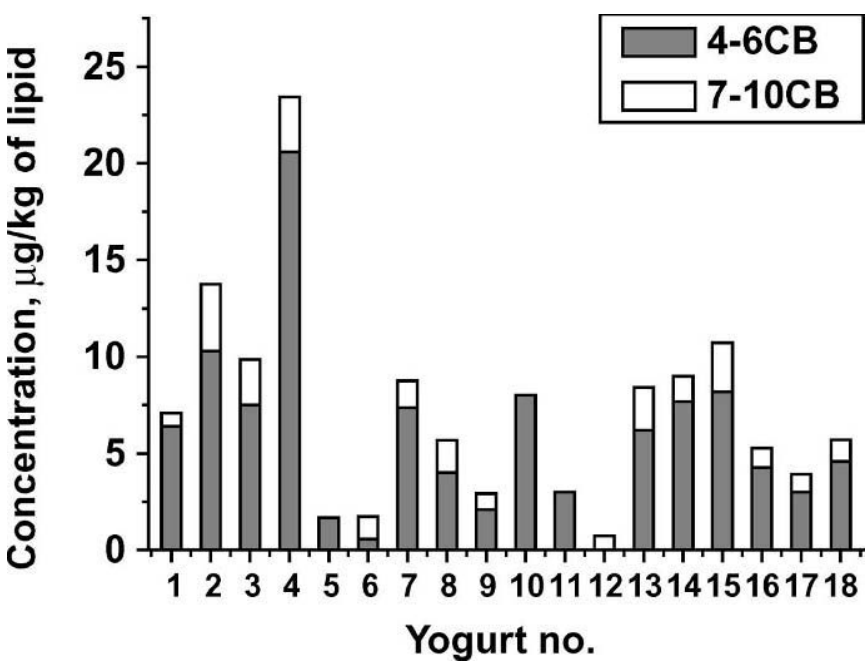

Figure 2. Concentration and composition of polychlorinated biphenyls (PCB) in 18 Chinese commercial yogurt samples; 4-6 chlorinated biphenyls (CB): $\Sigma(4 \mathrm{CB}+5 \mathrm{CB}+6 \mathrm{CB}) ; 7-10 \mathrm{CB}: \Sigma(7 \mathrm{CB}+8 \mathrm{CB}+9 \mathrm{CB}+$ $10 \mathrm{CB}) ; 4 \mathrm{CB}=\mathrm{PCB} 60 ; 5 \mathrm{CB}=\mathrm{PCB} 103+105 ; 6 \mathrm{CB}=\mathrm{PCB} 128+143+154 ;$ $7 \mathrm{CB}=\mathrm{PCB} 173 ; 8 \mathrm{CB}=\mathrm{PCB} 202+205 ; 9 \mathrm{CB}=\mathrm{PCB} 208 ; 10 \mathrm{CB}=\mathrm{PCB} 209$.

detected PCB in the yogurt samples, such as PCB60 $\left(2,3,4,4^{\prime}-\right), 103 \quad\left(2,2^{\prime}, 4,5^{\prime}, 6-\right), 105 \quad\left(2,3,3^{\prime}, 4,4^{\prime}-\right), 128$ $\left(2,2^{\prime}, 3,3^{\prime}, 4,4^{\prime}-\right), 143\left(2,2^{\prime}, 3,4,5,6^{\prime}-\right), 154\left(2,2^{\prime}, 4,4^{\prime}, 5,6^{\prime}-\right)$, $173\left(2,2^{\prime}, 3,3^{\prime}, 4,5,6-\right), \quad 202 \quad\left(2,2^{\prime}, 3,3^{\prime}, 5,5^{\prime}, 6,6^{\prime}-\right), 205$ $\left(2,3,3^{\prime}, 4,4^{\prime}, 5,5^{\prime}, 6-\right), 208\left(2,2^{\prime}, 3,3^{\prime}, 4,4^{\prime}, 5,6,6^{\prime}-\right)$, and 209 $\left(2,2^{\prime}, 3,3^{\prime}-, 4,4^{\prime}, 5,5^{\prime}, 6,6^{\prime}-\right)$ were almost all in accordance with the rule, suggesting that the $4,4^{\prime}$ - and $2,3,5$ - substitution patterns were characteristic of the PCB residues in yogurt.

PCB105. PCB105, one of dioxin-like PCB with a toxicity equivalency factor of 0.0001 , was detected in 4 yogurt samples, whose concentrations and toxic equivalent (TEQ) ranged from 0.7 to $2.2 \mu \mathrm{g} / \mathrm{kg}$ of lipid and 0.07 to $0.2 \mathrm{ng} / \mathrm{kg}$ of lipid, respectively. King et al. (1999) reported that TEQ of PCB contributed to $37 \%$ of total TEQ in British milk and a higher proportion (52\%) was observed in Dutch milk, which implied that PCB contamination in dairy products was a major concern.

\section{EPOCI in 18 Chinese Commercial Yogurt Samples}

The concentrations of EPOCl and the identified organochlorine compounds; that is, the sum of OCP and PCB determined by GC-electron capture detector expressed as chlorine, in 18 commercial brands of yogurt samples are listed in Table 3. The results indicated that 0.7 to $13.1 \%$ of total EPOCl were accounted for in the yogurt samples, which suggested that a major portion of $\mathrm{EPOCl}$ measured in yogurt remained uncharacterized. Because few reports on EPOCl in dairy products are available in literature, only a comparison with other
Table 3. The average concentration of identified $\mathrm{OC}^{1}$ and $\mathrm{EPOCl}^{1}$ in 18 Chinese commercial yogurt samples

\begin{tabular}{lcll}
\hline $\begin{array}{l}\text { Yogurt } \\
\text { no. }\end{array}$ & $\begin{array}{l}\text { Identified } \\
\text { OC, }{ }^{2} \mu \mathrm{g} / \mathrm{kg} \\
\text { lipid }\end{array}$ & $\begin{array}{l}\text { EPOCl, } \\
\mu \mathrm{g} / \mathrm{kg} \\
\text { lipid }\end{array}$ & $\begin{array}{l}\text { Unidentified } \\
\text { OC in } \\
\text { EPOCl, } \%\end{array}$ \\
\hline 1 & 45.2 & 1,400 & 97.0 \\
2 & 112.4 & 750 & 86.9 \\
3 & 19.7 & 950 & 98.0 \\
4 & 53.6 & 630 & 92.1 \\
5 & 15.2 & 180 & 92.4 \\
6 & 9.2 & 1,400 & 99.3 \\
7 & 52.7 & 950 & 94.7 \\
8 & 42.6 & 2,000 & 97.9 \\
9 & 38.1 & 1,100 & 96.5 \\
10 & 79.3 & 2,100 & 96.4 \\
11 & 10.4 & 640 & 98.4 \\
12 & 16.3 & 640 & 97.5 \\
13 & 24.5 & 1,300 & 98.1 \\
14 & 33.5 & 1,600 & 97.9 \\
15 & 40.8 & 1,200 & 96.6 \\
16 & 22.1 & 740 & 97.1 \\
17 & 19.6 & 980 & 98.0 \\
18 & 28.1 & 1,800 & 98.4 \\
\hline
\end{tabular}

${ }^{1} \mathrm{OC}=$ organochlorine compounds $; \mathrm{EPOCl}=$ extractable persistent organochlorine.

${ }^{2}$ Identified OC: the sum of detected target organochlorine pesticides and polychlorinated biphenyls expressed as chlorine.

biological or environmental samples could be made. Similar to our results, Gustavson and Mar (1999) reported that PCB contributed to less than 1.3 to $21 \%$ of $\mathrm{EPOCl}$ in surface sediment, and that $\mathrm{PCB}, \mathrm{HCH}$, and DDT contributed to less than 0.2 to $19 \%$ of EPOCl in blue mussels from the Baltic Sea. Other reports showed that 74 to $99 \%$ of extractable organochlorines in several species of fish (Newsome et al., 1993) and 80.6 to $98.6 \%$ of EPOCl in pine needles from China (Xu et al., 2003) could not be accounted for by PCB and OCP.

\section{CONCLUSIONS}

The contamination patterns of the selected OCP in yogurt samples were in the order of DDT $\approx \mathrm{HCH} \gg$ aldrin $\geq$ chlordanes $\geq$ heptachlor epoxide. The main contributors to OCP residues in yogurt were $\mathrm{HCH}$ and DDT, despite the long-time restrictions or bans of their use. Also, $\beta-\mathrm{HCH}$ and $\mathrm{p}, \mathrm{p}^{\prime}-\mathrm{DDE}$ were the predominant isomers of $\mathrm{HCH}$ and DDT in yogurt, respectively. The contamination patterns of the selected PCB in yogurt samples were in the order of $4-6 \mathrm{CB}>>7-\mathrm{CB}$, and $\mathrm{PCB}$, with 4,4'- and 2,3,5-substituted residues being the predominant congeners of PCB. Less than $4 \%$ of EPOCl can be explained by OCP and PCB in the studied yogurt samples. Our results indicate that an exposure risk of these pollutants to humans through dairy products and their impact on human health should not be neglected. 


\section{ACKNOWLEDGMENTS}

This work was funded by National Natural Science Foundation of China (Grant nos. 10490180 and 10275074), the Chinese Academy of Sciences (Grant KJCX-N01), International Atomic Energy Agency (Coordinated Research Project), and Science and Technology Foundation of Shenzhen, China (200209).

\section{REFERENCES}

Abou-Arab, A. A. K. 1997. Effect of Ras cheese manufacturing on the stability of DDT and its metabolites. Food Chem. 59:115-119.

Abou-Arab, A. A. K. 1999. Effects of processing and storage of dairy product on lindane residues and metabolites. Food Chem. 64:467-473.

Calamari, D., P. Tremolada, A. D. Guardo, and M. Vighi. 1994. Chlorinated hydrocarbons in pine needles in Europe: Fingerprint for the past and recent use. Environ. Sci. Technol. 28:429-434.

Chen, J. S., and J. Q. Gao. 1993. The Chinese total diet study in 1990. Part I. Chemical contaminants. J. AOAC Int. 76:1193-1205.

ENDS. 1997, Industry and scientists in cross fire on endocrine-disrupting chemicals. The ENDS report 268, (May): 26-29. Environmental Data Services.

Fries, G. F. 1977. The kinetics of halogenated hydrocarbon retention and elimination in dairy cattle. Pages 159-173 in Fate of Pesticides in the Large Animal. Academic Press, London, UK.

GB6914-1986. 1986, P.R. China, National Standard Method. Food and Agricultural Standards Research Center, China National Institute of Standardization, Beijing, China.

Gether, J., G. Lunde, and E. Steinnes. 1979. Determination of the total amount of organically bound chlorine, bromine and iodine in environmental sample by instrumental neutron activation analysis. Anal. Chim. Acta 108:137-147.

Geyer, H. J., I. Scheunert, and F. Korte. 1987. Correlation between the bioconcentration potential of organic environmental chemicals in humans and their n-octanol/water partition coefficients. Chemosphere 16:239-252.

Gustavson, K., and P. J. Mar. 1999. Some halogenated organic compounds in sediments and blue mussel (Mytilus edulis) in Nordic seas. Mar. Pollut. Bull. 38:723-736.

Jacobs, M. N., A. Covaci, A. Gheorghe, and P. Schepens. 2004. Time trend investigation of PCBs, PBDEs, and organochlorine pesticides in selected n-3 polyunsaturated fatty acid rich dietary fish oil and vegetable oil supplements; nutritional relevance for human essential n-3 fatty acid requirements. J. Agric. Food Chem. 52:1780-1788.

Jiang, K., L. Li, Y. Chen, and J. Jin. 1997. Determination of PCDD/ Fs and dioxin-like PCBs in Chinese commercial PCBs and emission from a testing PCB incinerator. Chemosphere 34:941-950.

Kalantzi, O. I., R. E. Alcock, P. A. Johnston, D. Santillo, R. L. Stringer, G. O. Thomas, and K. C. Jones. 2001. The global distribution of PCBs and organochlorine pesticides in butter. Environ. Sci. Technol. 35:1013-1018.

King, K., H. Fiedler, and D. B. Golder. 1999. Compilation of EU Dioxin exposure and health data: Human exposure and human levels. Organohalogen Compounds 44:161-164.

Koopman, E. C., K. N. Weisglas, R. M. De, D. P. C. Van, L. Tuinstra, and P. Sauer. 1996. Effects of polychlorinated biphenyl/dioxin exposure and feeding type on infants' mental and psychomotor development. Pediatr. Res. 97:700-706.

Kunisue, T., M. Someya, F. Kayama, Y. Jin, and S. Tanabe. 2004. Persistent organochlorines in human breast milk collected from primiparae in Dalian and Shenyang, China. Environ. Pollut. 131:381-392.

Matthews, H. B., and R. L. Dedrick. 1984. Pharmacokinetics of PCBs. Annu. Rev. Pharmacol. Toxicol. 24:85-103.

McLachlan, M. S. 1993. Mass balance of polychlorinated biphenyls and other organochlorine compounds in a lactating cow. J. Agric. Food Chem. 41:474-480.

Newsome, W. H., P. Andrews, B. S. Conacher, R. R. Roa, and A. Chatt. 1993. Total organochlorine content of fish from the Great Lakes. J. AOAC 76:703-706.

Qin, Z. F., J. M. Zhou, S. G. Chu, and X. B. Xu. 2003. Effects of Chinese domestic polychlorinated biphenyls (PCBs) on gonadal differentiation in Xenopus laevis. Environ. Health Perspect. 111:553-556.

Tanabe, S., F. Gondaira, A. Subramanian, A. Ramesh, D. Mohan, P. Kumaran, V. K. Venugopalan, and R. Tatsukawa. 1990. Specific pattern of persistent organochlorine residues in human breast milk from south India. J. Agric. Food Chem. 38:899-903.

Venant, A., S. Borrel, and J. Mallet. 1991. Organochlorine compounds contaminants in milk and dairy products from 1975-1989. Lait 71:107-116.

WHO/FAO. 1978. 1977 Evaluations of some pesticide residues in food. World Health Organisation/Food and Agriculture Organization, Rome, Italy.

WHO/FAO. 1998. Codex Alimentarius: Volume 2B: Pesticide residues in food: Maximum residue limits. World Health Organisation/ Food and Agriculture Organization, Rome, Italy.

Willett, K. L., E. M. Ulrich, and R. A. Hites. 1998. Differential toxicity and environmental fates of hexachlorocyclohexane isomers. Environ. Sci. Technol. 32:2197-2207.

Wong, C. K. C., K. M. Leung, B. H. T. Poon, C. Y. Lan, and M. H. Wong. 2002. Organochlorine hydrocarbons in human breast milk collected in Hong Kong and Guangzhou. Arch. Environ. Contam. Toxicol. 43:364-372.

Wong, S. K., and W. O. Lee. 1997. Survey of organochlorine pesticide residues in milk in Hong Kong (1993-1995). J. AOAC 80:13321335.

Xu, D. D., W. K. Zhong, L. L. Deng, Z. F. Chai, and X. Y. Mao. 2003. Levels of extractable organohalogens in pine needles in China. Environ. Sci. Technol. 37:1-6.

Zhang, Y. 1995. Levels of organochlorine pesticides residues in food of China. Pesticide Manag. 6:20-22. [in Chinese]

Zhong, W. K., D. D. Xu, Z. F. Chai, and X. Y. Mao. 2003. 2001 survey of organochlorine pesticides in retail milk from Beijing, P. R. China. Food Addit. Contam. 20:254-258. 